\title{
Synthesis, growth of semiorganic TGDCC (Tetra Glycine Dihydrated Calcium Chloride) single crystal and a study of effect by Urea on the structural and optical properties
}

\author{
S.Thiyagaraj ${ }^{1}$, Dr.G.Meenakshi ${ }^{*}$ \\ ${ }^{1}$ Research scholar, Karpagam University, Coimbatore, India \\ "Associate Professor, K.M.C.P.G Studies, Puducherry, India
}

\begin{abstract}
Tetra Glycine dihydrated Calcium Chloride (TGDCC) single Crystal has been grown by slow evaporation techniques. Urea has been introduced by concentration ratio to the parental crystal. The investigation of this research work is to find the rate of change of optical and structural behaviors of the crystal by urea through $U V$-Vis, P-XRD, XRD, FTIR and SHG studies.
\end{abstract}

Keywords - Slow evaporation solution growth, UV-vis, P-XRD, XRD, FTIR, and SHG studies.

Accepted Date: 15 June 2013

\section{Introduction :}

The world of modern technology is identified the study of crystal growth and characterization was one of the fascinating fields of research. Growth of single crystal can be regarded as a phase transformation into solid State from the solid, liquid and vapour state (Govindhan danaraj et al 2010). The Semiorganic single crystal like, glycine ( Glycine with calcium chloride (Iyanar M et al 2009), Ammonium sulfate(Anbuchudar et al 2010), hydrofluoric acid (Surekha $R$ et al 2011), and sodium acetate (Baraniraja $T$ et al 2011), Urea thiourea sodium chloride(Ushasree PM et al 2008), Bis thiourea cadmium chloride( Gopinath $S$ et al 2012), L-arginine per chlorate crystal(Tapati Malik et al 2009) and sodium P-nitrophenolate dihydrated crystal(Milton Boaz et al 2009) ) plays an important role in various industries like medicine, and horticulture fields and also gained considerable interest because of their potential application towards the growth of human, animal and plants. The Glycine is a simplest amino acid that has three polymeric crystalline forms, $\alpha, \beta$ and $\gamma$. Both $\alpha$ and $\beta$ forms crystalline in centrosymmetric space group P21/c (Xia Yang et al 2008, Ambujam $K$ et al 2006). $\gamma$-glycine crystallizes in noncentrosymmetric Space group P31 making it a potential candidate for piezoelectric and nonlinear optical (NLO) applications. The carboxylic acid group present in the $\gamma$-glycine donates its proton to the amino group and it forms the structure $\mathrm{NH}_{3}^{+} \mathrm{CH}_{2} \mathrm{COO}^{-}$. Thus in solid state, $\gamma$-glycine exists as a dipolar ion in which carboxyl group is present as a Carboxylate ion and amino group is present as ammonium ion (Sivanesan T et al 2010). Adding impurities with glycine gives more effective in the field of crystal growth. In general, glycine with urea used to synthesis a creatine (Fisher $\boldsymbol{R B}$ et al 1940). The creatine is naturally produced in the human body from amino acid primarily in the kidney and liver. It has been transported in the blood for the use by muscle which was approximately $95 \%$ of human body. Total creatine has been located in the skeletal muscle and it is used by athletes, body builders, wrestlers, sprinters to grow muscle mass by 2 to 3 times greater than normal person. Mostly it is found to be very high in pasteurized cow's milk (Hulsemann J. Manz F et al 1987, Theo wallimann et at 2011). Earlier the effects of urea and calcium chloride and their combination on qualitative and quantitative characteristics of pomegranate plant have been investigated. The result implies that, adding urea and calcium chloride to glycine, it increases the size of the fruit and its ascorbic acid content (Asghar ramezanian et al 2009). Therefore walking towards the Amino acid with urea research, gives more interaction with society of the researchers. This research work is trying to utilize the basic idea and the concept of specimen chosen. Form this study author would like to find out the rate of change of optical and structural behaviors of glycine di-hydrated calcium chloride crystal by the impact of urea through UV, XRD, FTIR, and SHG studies. The future work of this research can be used to find the character deviation of the plant growth by the impact of urea at different concentration.

\section{Experimental Techniques}

The experiment was carried out in two parts. In a first part the $4 \%$ (molecular ratio) of glycine (Merck) and $1 \%$ (molecular ratio) of dihydrated calcium chloride (Merck) has been taken for the synthesis. This 4:1 ratio constituent was dissolved in $500 \mathrm{ml}$ double distilled water. The saturated solution was filtered by wattmann filter 41 paper and the filtered solution was poured into petridish and beaker for crystal growth process. In part 
2, the 50 grams of urea dissolved in $500 \mathrm{ml}$ double distilled water (0.1concentration) and filtered by wattmann filter 41. The glycine and dihydrated calcium chloride (4:1) dissolved in this solution. The filtered super saturated solution has been poured into petridish and beaker for the growth process. The harvested crystals (Fig$1,2)$ are used to find the rate of change of optical and structural properties from its parental properties by the urea impact.

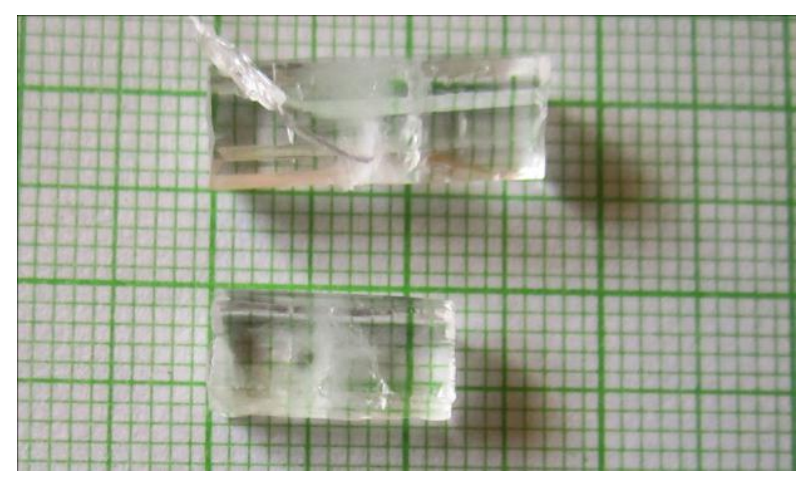

Fig-1: TGDCC Crystal (Urea undoped)

\section{Characterization Studies}

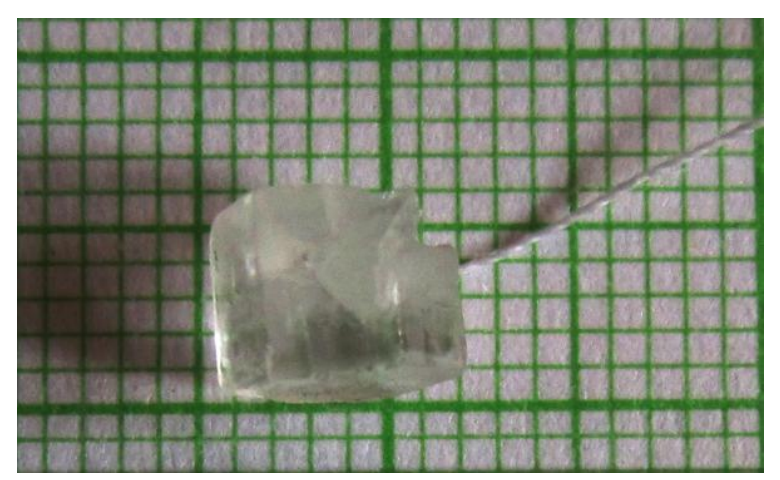

Fig-2: Urea (0.1cons) doped TGDCC Crystal

The property, property deviation of harvested semiorganic single crystal has been investigated through UV-Vis, P-XRD, XRD, FTIR and SHG studies. The absorption and transmission property of the crystal has been carried out by UV-Vis spectral analysis for urea doped, and undoped crystal. The P-XRD, XRD investigation was used to identify the lattice parameters, space groups and the system of titled crystal, urea doped crystal. The presence of functional groups has been identified by FTIR spectral analysis. The study of second harmonic generation (SHG) has been carried out by Kurtz powder technique to confirm its NLO efficiency.

\section{A. $\boldsymbol{U} \boldsymbol{V}$-Vis studies}

The optical property of TGDCC crystal was investigated by UV-Vis Studies. The result implies that the transparency of the crystal slightly reduced when urea doped within it. The absorption graph of undoped urea (Fig- 3a) indicates that, the absorption occurs at $198.28 \mathrm{~nm}$. After this wave length, gradual decline occurs in absorption peak. At exactly $235 \mathrm{~nm}$ the absorption peaks intersect with zero absorption. It indicates that above $235 \mathrm{~nm}$ the crystal has high transparency. This is the basic quality of NLO crystal. Urea doped TGDCC crystal holds two absorption peaks. It is appears near 203.17 and $198.27 \mathrm{~nm}$ (Fig- 3a). After that, it also gradually decreases and the absorption line lies at $280 \mathrm{~nm}$. Therefore above this wave length it has high transparency. The wave length of $45 \mathrm{~nm}$ shifted from undoped to doped material (Fig-3b). It shows that the absorption wave length slightly increases with doping the urea to TGDCC crystal. It was confirmed in transparency graph (Fig-3b).

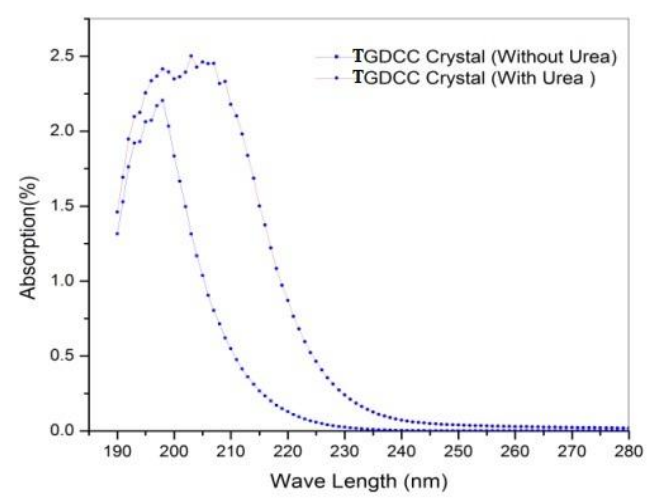

Fig.3a

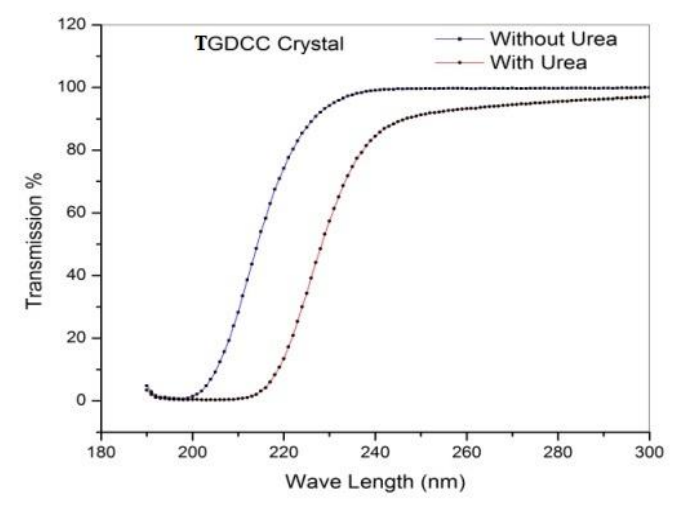

Fig. 3b 


\section{B. Powder XRD, XRD Analysis:}

The powder form of the specimen was placed at XPERT-PRO Powder X-ray diffractometer. The anode material of this diffractometer was $\mathrm{Cu}$ and $\mathrm{K}$-Alpha1, K-Alpha2 wave lengths are 1.540 and 1.544 . The minimum two theta step size is 0.001 and 0.001 for omega. The sample was scanned over the range of 10-70 degrees at 19.685 times per step and each scan step size is 0.016 . The recorded spectrum was shown in figure 4 . The lattice parameters have been calculated with the help of Treor 90 function for both urea doped and undoped to TGDCC crystal. The lattice parameter values for undoped urea specimen was $a=7.02 \AA, b=7.02 \AA$, $c=5.48 \AA$ and $\alpha=\beta=90.00^{\circ}, \gamma=120.00^{\circ}, V=234 \mathrm{~A}^{3}$ and the crystal system of TGDCC is hexagonal. For urea doped material $a=7.00 \AA, b=7.00 \AA ⿻, c=5.46 \AA$ and $\alpha=\beta=90.00^{\circ} \gamma=120.00, V=231 \mathrm{~A}^{3}$. This report implies that, the both crystals are having same crystal system. The XRD data for both crystals were investigated and its cell parameters were confirmed from Indian institute of technology, Chennai. From this investigation one can clearly identify that the crystal size may reduce when urea was introduced into it.

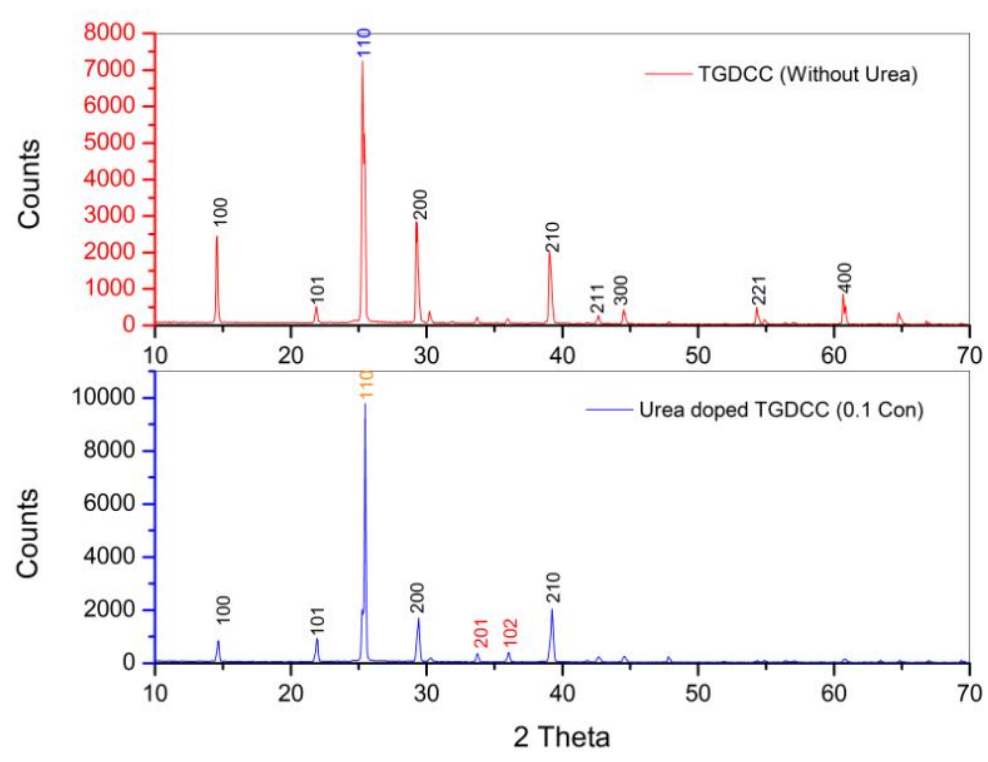

Fig: 4 P-XRD pattern of urea doped, undoped TGDCC crystal:

\section{FTIR Studies}

i) To identify the chemical compositions of Urea doped, undoped to GDCC crystal, its powder sample were subjected to FTIR investigator. The result was found to be that there was no remarkable changes occur in the transmission wave lengths, except a slight change that too, only in the transmission intensity of the doped crystal. The comparison graph implies that, the urea doped crystal have higher transmission (Red line) wave Lengths (Fig. 5). The chemical composition and assignment of vibration of grown crystals are tabulated in table 1 .

ii) $\mathrm{NH}_{3}^{+}$Stretching Vibration:

Generally free amino acids exist as zwitter ions. They are characterized by IR frequency band appears near $3100-2600 \mathrm{~cm}^{-1}$. It was due to $\mathrm{NH}_{3}^{+}$Stretching. Here the calculated frequency band appears at 3091,2729 , $2601 \mathrm{~cm}^{-1}$. It was because of glycine acts as zwitter ions and also proton accepter. Similarly, the salt of primary amine shows a strong band that appears in the region of infrared frequency between $3000 \mathrm{Cm}^{-1}-$ $2800 \mathrm{~cm}^{-1}$. It was due to Asymmetric and Symmetric vibration of $\mathrm{NH}_{3}^{+}$groups and the further combination band occurs in the region of $2800-2000 \mathrm{~cm}^{-1}$. FTIR frequency of Urea doped and without urea doped titled crystal bands occurs at $2729 \mathrm{~cm}^{-1}$ and $2601 \mathrm{~cm}^{-1}$. 


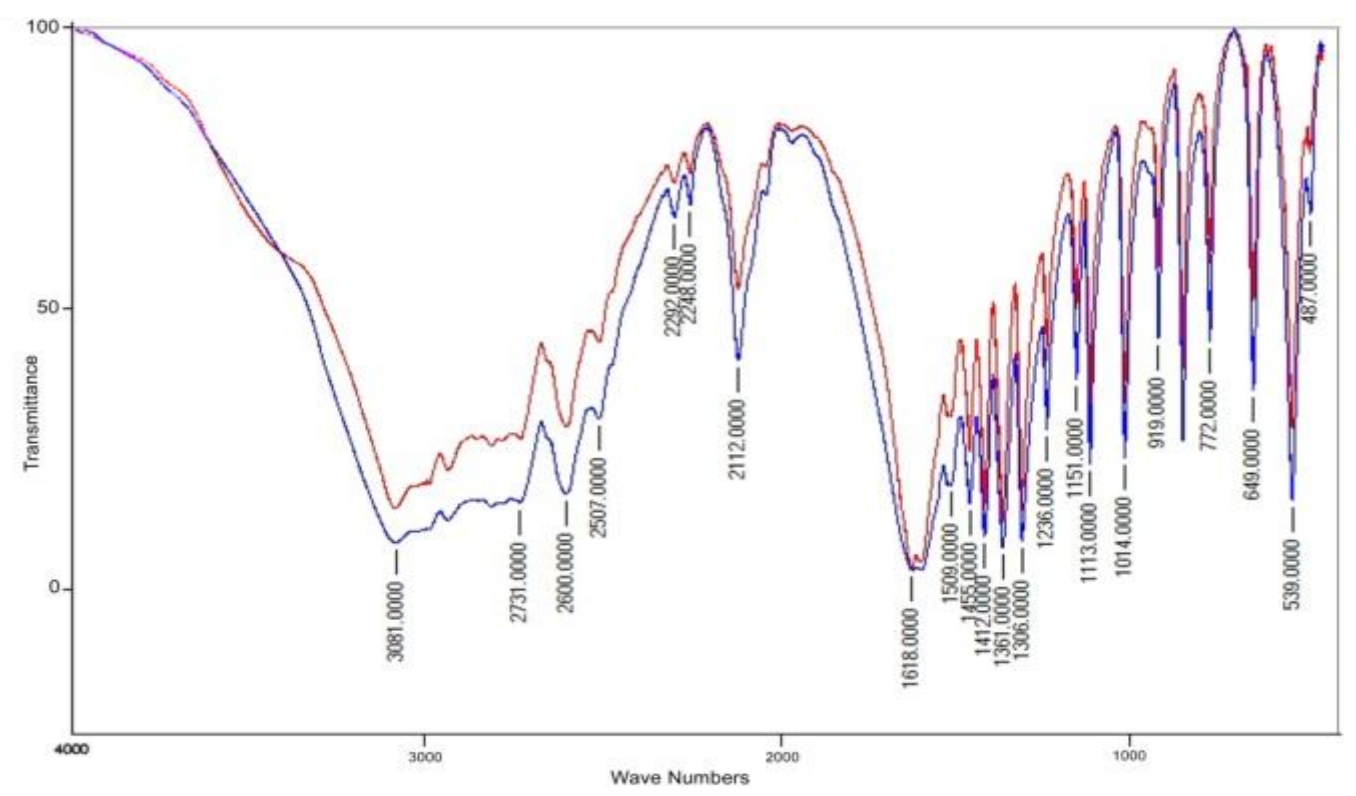

Fig-5: FTIR Spectrum of TGDCC Crystal(With and Without Urea)

\section{i. Super imposed $\mathrm{O}-\mathrm{H}$ and $\mathrm{NH}_{3}^{+}$stretching:}

Hydrochlorides of amino acids show a broad strong absorption frequency in the region of $3300 \mathrm{~cm}^{-1}$ and $2400 \mathrm{~cm}^{-1}$. The calculated FTIR frequency of Urea doped and Undoped to TGDCC crystal occurs in the same absorption region with multiple fine low frequencies, Such as $3091,2729,2601,2502,2464 \mathrm{~cm}^{-1}$. It may be due to super impossibly of $\mathrm{O}-\mathrm{H}$ and $\mathrm{NH}_{3}^{+}$stretching.

\section{ii. Combination of Asymmetric $\mathrm{NH}_{3}^{+}$bending vibration and torsional motion:}

The multiple combination overtone bands extended the absorption to $2000 \mathrm{~cm}-1$. This overtone region usually contain a prominent band near $2000-2200 \mathrm{~cm}-1$ for free amino acids but torsional mode occurs near $500 \mathrm{~cm}^{-1}$. This was assigned to a combination of the asymmetrical $\mathrm{NH}_{3}^{+}$bending vibration and torsional motion of $\mathrm{NH}_{3}^{+}$groups. The absorption spectral lines of Urea doped and without doped titled crystal had two frequencies $2111,2029 \mathrm{~cm}^{-1}$ and $540 \mathrm{~cm}^{-1}$ in this same region.

\section{iii. $\quad C=O$ and $C-N$ stretching vibration:}

The $\mathrm{C}=\mathrm{O}$ Stretching frequency of urea appears at $1687 \mathrm{~cm}^{-1}$. But for solid, this frequency has been reduced or decreased to $1505 \mathrm{~cm}^{-1}$, while C-N stretching frequency of urea occurs at $1467 \mathrm{~cm}^{-1}$. If it was of solid form this frequency value shows an increment by $40 \mathrm{~cm}^{-1}$. The FTIR frequency peaks of titled crystal with urea doped or non doped material has 1608,1505 , and $1454 \mathrm{~cm}^{-1}$ frequencies in the same region. It was because of the impact of urea on titled crystal and bonding with metal through oxygen. At the same time the N-H stretching frequency does not show any shift. There was no evidence for coordination of urea through nitrogen possibly since it involves loss of delocalization energy (Sathiyanarayanan DN et al 2004). The stretching vibration of the triply bonded group occurs between $2500 \mathrm{~cm}^{-1}$ and $2000 \mathrm{~cm}^{-1}$. The group C triple bond to $\mathrm{N}$ gives rise to a strong absorption in the $2300-2200 \mathrm{~cm}-1$ region. The calculated frequency of titled crystal occurs at 2249 and $2292 \mathrm{~cm}^{-1}$.

\section{iv. C-O stretching and $\mathrm{O}-\mathrm{H}$ bending vibration:}

There were two bands arising in infrared spectral lines for carboxylic acids. One for C-O stretching was in the range of 1320 to $1210 \mathrm{~cm}^{-1}$ and the other for O-H arising from 1440 to1400 $\mathrm{cm}^{-1}$. The FTIR frequency for titled crystal occurs at 1362 and $1237 \mathrm{~cm}^{-1}$. This was due to C-O stretching at and $\mathrm{O}-\mathrm{H}$ stretching vibration of the same specimen occurs at $1411 \mathrm{~cm}^{-1}$. Therefore these bonds involved in interaction between $\mathrm{C}-\mathrm{O}$ stretching and $\mathrm{C}-\mathrm{O}-\mathrm{H}$ bending vibration. Generally, this bending vibrational mode arises near $1440 \mathrm{~cm}^{-1}$ to $1400 \mathrm{~cm}^{-1}$ as a band of moderate intensity and it was found to be in the same region as $\mathrm{CH}_{2}$ bending mode of $\mathrm{CH}_{2}$ group adjacent to a carboxylic carbon.

v. Rocking vibration: 
For the amino acid, the rocking vibration was assigned at $1235 \mathrm{~cm}^{-1}$ and $1115 \mathrm{~cm}^{-1}$. Similarly, the rocking vibration of titled specimen occurs in between 1237 to $1112 \mathrm{~cm}^{-1} 1$. It may be due to rocking vibration of $\mathrm{C}-\mathrm{O}$ stretching and $\mathrm{O}-\mathrm{H}$ bending vibration of the molecules.

Table-1: The chemical composition and assignment of vibration of grown crystal.

\begin{tabular}{|c|c|c|}
\hline $\begin{array}{l}\text { Calculated } \\
\text { frequency }\left(\mathrm{cm}^{-1}\right)\end{array}$ & $\begin{array}{c}\text { Observed } \\
\text { frequency }\left(\mathrm{cm}^{-1}\right)\end{array}$ & Assignment of vibration \\
\hline 3091 & $2500.3300(\mathrm{~m}-\mathrm{w})$ & Mostly broad, O.H stretching vibration \\
\hline 2729 & $2730.2730(\mathrm{~s})$ & $\mathrm{CH}_{3}$ stretching vibr ation \\
\hline 2601 & $2280-3330(\mathrm{~m})$ & Asymmetric N.H stretching vibration-dilute solution \\
\hline 2502 & $2500 \cdot 2500(w)$ & $\mathrm{CH}_{3}$ stretching vibration \\
\hline 2469 & $2280.3380(\mathrm{~m})$ & Asymmetric N-H stretching vibration- dilute solution \\
\hline 2292 & $200 \cdot 2360(w)$ & OH stretching vibration \\
\hline 2249 & $2035.2100(w)$ & C.C stretching vibration \\
\hline 2111 & $2100-2140(\mathrm{w}-\mathrm{m})$ & C.C stretching vibration \\
\hline 1608 & $1610.1640(\mathrm{~m})$ & $C=C$ stretching vibration \\
\hline 1506 & $1500 \cdot 1580$ & $C=C$ stretching vibration \\
\hline 1454 & $1440-1465(\mathrm{~m})$ & Asymmetric C.H deform tion vibration \\
\hline 1411 & $1395-1440(w)$ & C.Ostretching and $\mathrm{OH}$ - deformation vibration \\
\hline 1362 & $1335-1440(\mathrm{~m}-\mathrm{w})$ & Symmetric $\mathrm{CO}_{2}$ stretching vibration \\
\hline 1237 & $1090 \cdot 1255(w)$ & - $\mathrm{NH}_{3}+$ rodking vibration \\
\hline 1151 & $1130-1150(\mathrm{~m})$ & C.C rodking vibration \\
\hline 1112 & $1075.1190(S)$ & C.Ostretching vibration \\
\hline 1013 & $1010-1010(\mathrm{~m})$ & Symmetric N-C-N stretching vibration \\
\hline 918 & $915.955(\mathrm{~s})$ & Out-of-plane deformation vibration \\
\hline 852 & $700 \cdot 900(s)$ & $\mathrm{CH}_{3}$ metal groups due $\mathrm{CH}_{2}$ rodking vibration \\
\hline 773 & $770.785(w-m)$ & C.C skeleton vibration \\
\hline 540 & $535.555(w)$ & C.C skeleton vibration \\
\hline 484 & $450-500$ & M-Ostretching \\
\hline
\end{tabular}

\section{NLO studies:}

The Non-Linear Optical Studies were investigated for the above two samples by powder Kurtz technique and it was compared with the NLO properties of KDP Crystal. The SHG output of KDP is $53 \mathrm{mV}$. The SHG output of undoped sample was $76 \mathrm{mV}$ and for doped was $78 \mathrm{mV}$. It shows that the NLO property of undoped crystal was found to be 1.43 times grater than KDP crystal and doped crystal was 1.47 times grater than KDP crystal (Table-2).

Table-2: SHG -NLO efficiency Report:

\begin{tabular}{|c|c|}
\hline SAMPLE & OUTPUT \\
\hline KDP (Reference sample) & $53 \mathrm{mV}$ \\
\hline TGDCC Crystal (Urea undoped) & $76 \mathrm{mV}$ \\
\hline TGDCC Crystal (Urea undoped) & $78 \mathrm{mV}$ \\
\hline
\end{tabular}




\section{Result And Discussion}

Crystal growth was a fine art. This is used to know the material characters effortlessly. Particularly, slow evaporation techniques can identify the rate of growth and deviation of its characters. In this investigation the titled Crystal was grown by the slow evaporation techniques. So many researchers have introduced some organic or inorganic materials and urea in molecular ratio to the parental crystal. This research work was purely different from those methods. Here, urea was introduced by volume fraction with the titled crystal. The deviation in structural and optical behaviors of the TGDCC crystal by the impact of urea has been investigated through UV, XRD, FTIR, and SHG studies.

\section{Conclusion}

From the UV investigation, when the crystal was doped with urea, its transparency abruptly reduced. The lattice parameter of the doped, undoped titled crystal has been found by treor function and also the XRD data for these crystals were reported from IIT. From these report, the volume of urea doped crystal has low value to compare with undoped material. This may increase two theta values and reduce the density of the material and crystalline size. Hence the crystal attains some changes in its structure. The report form SHG confirms that, the urea doped and undoped crystal was 1.47 and 1.43 times greater to compare with KDP crystal. Hence it may be used for NLO application. FTIR investigation charted out all the chemical compositions of the material. Hence, the concentrated method urea doping techniques may revolutionize some countable changes in the structure and the optical properties of the material.

\section{Acknowledgement}

Author would like to express his thanks to Dr.A.Ravichandran, Principal, Christ College of Engineering and Technology, puducherry, for providing mechanical lab, digital lab facilities and for his constant encouragement. Author would like to articulate his sincere thanks the head, Department of physics, St.Joseph's college of Arts and Science, Cuddalore to write up the graphical elucidation to his research work. Finally the author likes to thank the faculties of department of physics, and Mechanical engineering, Christ College of Engineering and Technology, Puducherry for their manual support and their encouragements.

\section{References}

[1]. Ambujam K, Selvakumar S, Premanand D, Mohamed G and Sagayaraj P, 2006, J.Cryst. Res.Tech, 41 671

[2]. Anbuchudar Azhagan S, Ganesan S, 2010, Resent research in Sci.Tech, 2107

[3]. Asghar ramezanian, Majid rahemi, Mohammed rezavazifehshenas, 2009, J. Scientia horticulture, 121171

[4]. Baraniraja T, Philominathan P, 2011, J. Minerals, Material Charac Engin, 10351

[5]. Fisher R B, Wilhelmi A E, 1940, J. Biol. Chem, 132135

[6]. Gopinath S, Barathan S, Rajasekaran R, 2012, J. Therm analys and calorimet, 110789

[7]. Govindhan danaraj, Kullaiah Byrappa, Viswanath Prasath, Michael Dudley, 2010, Springer hand book of Cryst. Growth, 3

[8]. Hulsemann J.Manz F, Wember T, Schoch G, 1987, J.Klin Padiatr, 199295

[9]. Iyanar M, Thomas Joseph Prakash J, Muthamizhchelvan C and Ponnusamy S, 2009, J.Physical.Sci,13 235

[10]. Milton Boaz B, Samuel selvaraj R, Senthil Kumar K and Jerome Das S, 2009, Indian. J. Phys, 831647

[11]. Sathiyanarayana D N, 2004, Vibrational Spectroscopy theory and Applications, New Age Inter Pub

[12]. Sivanesan T, Natarajan V, Pandi S, 2010, Asn. J.Chem, 224229

[13]. Surekha R, Gunaseelan R and Sagayaraj P, 2011, Arch. Applied. Science.Rec, 3280

[14]. Tapati Mallik, Tanusri Pal and Tanusree Kar, 2009, Indian.J.Phys, 831395

[15]. Theo Wallimann, Malgorzata Tokaraska- Schlattner, Uwe Schlatter, 2011, J. Amino acid, 401277

[16]. Ushasree PM, Muralidharan R, Jayavel R and Ramasamy P, 2008, J.Cryst.Growth, 218365

[17]. Xia Yang, Jie Lu, Xiu-Juan Wang, Chi- Bun Ching, 2008, J. Cryst. Growth, 310604. 